
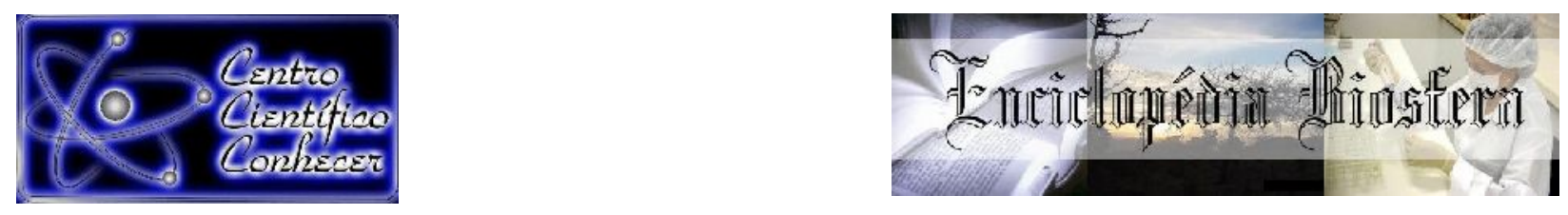

\title{
ENSINO-APRENDIZADO DE CIÊNCIAS SOCIAIS APLICADAS E ENGENHARIAS IV INTEGRADO À REALIDADE VIRTUAL E AUMENTADA
}

\author{
Jonathan Felipe da Silva ${ }^{1}$, Sandro César Silveira Jucá ${ }^{2}$, Solonildo Almeida da Silva ${ }^{3}$, \\ Pedro Bruno Silva Lemos ${ }^{1}$ \\ ${ }^{1}$ Doutorando em Ensino (RENOEN) pelo Instituto Federal de Educação, Ciência e \\ Tecnologia do Ceará (IFCE), Fortaleza-CE, Brasil. \\ ${ }^{2}$ Doutor em Engenharia Elétrica, Professor do Instituto Federal de Educação, \\ Ciência e Tecnologia do Ceará (IFCE), Maracanaú-CE, Brasil. \\ ${ }^{3}$ Doutor em Educação, Professor do Instituto Federal de Educação, Ciência e \\ Tecnologia do Ceará (IFCE), Maracanaú-CE, Brasil. \\ E-mail: jonathan.silva@ifce.edu.br
}

\section{Recebido em: 15/08/2021 - Aprovado em: 15/09/2021 - Publicado em: 30/09/2021 \\ DOI: 10.18677/EnciBio_2021C34}

trabalho licenciado sob licença Creative Commons Attribution-NonCommercial-NoDerivatives 4.0 International License.

\begin{abstract}
RESUMO
O conhecimento relacionado às áreas das Ciências Sociais Aplicadas e das Engenharias IV avançou, nas últimas décadas, em um ritmo considerável. Desta forma, houve uma urgência para a adoção de estratégias didáticas que proporcionassem ao aluno das disciplinas pertencentes a estas áreas a oportunidade de construir um aprendizado ainda mais eficaz e que mitigasse dificuldades recorrentes, como a dificuldade da visualização tridimensional de elementos relacionados aos conteúdos abordados. Em razão disto, as Tecnologias de Informação e Comunicação (TICs) se apresentam como ferramentas de auxílio e que permitem uma abordagem interdisciplinar. A presente pesquisa aborda conceitos e propostas inovadoras de utilização das TICs relacionadas à Realidade Virtual (RV) e Realidade Aumentada (RA) no ambiente das áreas de Ciências Sociais Aplicadas e Engenharias IV, através de uma revisão bibliográfica de diversos livros e artigos de notável relevância nos seus respectivos temas. Foi realizada uma revisão de abordagem do tipo qualitativa de temas como a formação, prática docentes, metodologias ativas, didática profissional e utilização da RA e RV voltadas para estas áreas, além de revisão sobre as TICs no âmbito do ensino e do aprendizado. Após a revisão dos conceitos existentes, foram indicados desafios e sugestões inovadoras, baseados em ações de sucesso oriundas de análise bibliográfica, das práticas pedagógicas voltadas à atividade de ensino - aprendizado dos campos das Ciências Sociais Aplicadas e Engenharias IV.
\end{abstract}

PALAVRAS-CHAVE: Didática profissional. Metodologias ativas. Prática docente. Tecnologias. 


\title{
TEACHING LEARNING IN APPLIED SOCIAL SCIENCES AND ENGINEERING IV INTEGRATED TO VIRTUAL AND AUGMENTED REALITY
}

\begin{abstract}
The knowledge related to the areas of Applied Social Sciences and Engineering IV has advanced, in the last decades, at a considerable pace. Thus, there was an urgency for the adoption of didactic strategies that would provide the student of subjects belonging to these areas with the opportunity to build an even more effective learning and to mitigate recurrent difficulties, such as the difficulty of threedimensional visualization of elements related to the contents covered. As a result, Information and Communication Technologies (ICTs) are presented as help tools that allow for an interdisciplinary approach. This research addresses innovative concepts and proposals for the use of ICTs related to Virtual Reality (VR) and Augmented Reality (AR) in the field of Applied Social Sciences and Engineering IV, through a literature review of several books and articles of remarkable relevance in their respective themes. A qualitative approach review of topics such as training, teaching practice, active methodologies, professional didactics and the use of AR and VR aimed at these areas was carried out, as well as a review of ICTs in the context of teaching and learning. After reviewing the existing concepts, challenges and innovative suggestions were indicated, based on successful actions arising from bibliographic analysis, pedagogical practices aimed at teaching activities - learning in the fields of Applied Social Sciences and Engineering IV.
\end{abstract}

KEYWORDS: Professional didactics. Active methodologies. Teaching practice. Technologies.

\section{INTRODUÇÃO}

O ensino-aprendizado das disciplinas voltadas às áreas de Ciências Sociais Aplicadas e daquelas relativas às Engenharias IV , nas últimas décadas, avançou de forma considerável. Novas estratégias foram desenvolvidas para proporcionar ao professor e ao aluno uma melhoria no processo de ensino-aprendizado. Os métodos clássicos de ensino baseados na acentuada memorização do conteúdo e na escassez no uso de instrumentos tecnológicos estão cada vez mais sendo substituídos por estratégias didáticas baseadas nas metodologias ativas, em que a tecnologia esteja cada vez mais presente como um importante instrumento voltado para o aprendizado.

Entende-se como Ciências Sociais Aplicadas, conforme a Coordenação de Aperfeiçoamento de Pessoal de Nível Superior (CAPES) ${ }^{1}$, aquelas áreas pertencentes à Arquitetura e Urbanismo, Desenho Industrial, Comunicação, entre outras. Em relação às Engenharias IV, ainda segundo o portal CAPES, abrangem os Cursos e Programas de Pós-Graduação de Engenharia Elétrica e Engenharia Biomédica.

Em relação ao ensino-aprendizado na área de Ciências Sociais Aplicadas, na atualidade, nota-se que o professor teve que buscar uma constante atualização, devido ao grande número de avanços científicos em um curto espaço de tempo. Além disso, a indisponibilidade de um espaço de trabalho e materiais adequados para a maioria destes professores representa um desafio para atingir os objetivos

\footnotetext{
Classificação das áreas conforme indicado pela Coordenação de Aperfeiçoamento de Pessoal de Nível Superior (CAPES). Disponível em: <https://www.gov.br/capes/pt-br/acesso-a-informacao/acoese-programas/avaliacao/sobre-a-avaliacao/areas-avaliacao/sobre-as-areas-de-avaliacao/sobre-asareas-de-avaliacao>. Acesso em ago 2021.
} 
pretendidos para a aula (MARTINS, 2005).

Para que o discente seja estimulado a experimentar, pesquisar e compreender a Ciência, é necessário que as aulas sejam dinâmicas e capazes de estimular o discente a também produzir conhecimento. Tanto no nível básico quanto no nível superior, encontra-se o semelhante desafio: como tornar a aula interessante, a fim de que o discente possa questionar, experimentar e gerar conhecimento? Lima e Stella (2020) trazem uma reflexão nesta linha de pensamento, ao investigar os conflitos entre professor e aluno, fazendo com que haja uma maior potencialização do aprendizado.

Este questionamento estende-se também para as disciplinas pertencentes às áreas das Engenharias IV. O atual avanço da globalização econômica e da concorrência proporcionaram um aumento notável na exigência de capacitação dos engenheiros. A grande quantidade de profissionais recém formados não é devidamente absorvida pelo mercado de trabalho. Além disso, novos conhecimentos elaborados passaram a ser exigidos para os engenheiros em formação, sendo necessário buscar novos modelos de ensino, visando a um aprendizado mais efetivo.

Este trabalho destaca, através de uma revisão bibliográfica, o problema em comum encontrado no ensino de Ciências Sociais Aplicadas e de Engenharias IV, no modelo em que usualmente é adotado: aulas com características tradicionais, sendo o professor o detentor do conhecimento em sala, e o aluno assumindo um papel passivo. Desta forma, o conteúdo abordado não seria aprendido da forma como foi planejada previamente pelo docente. Apesar de algumas disciplinas pertencentes a estas áreas exigirem o método tradicional de ensino, como aquelas voltadas para o cálculo ou abordagem da legislação, aquelas centradas em atividades práticas, como por exemplo as relacionadas a projetos, simulações e aulas de campo, podem assumir a possibilidade de inserção de ferramentas tecnológicas para facilitar a compreensão através da visualização tridimensional.

A hipótese está baseada na utilização de recursos tecnológicos para mitigar esta dificuldade observada no processo de ensino-aprendizado das áreas citadas anteriormente, focando na realidade virtual $(R V)$ e realidade aumentada (RA) como meios de potencialização do nível de aprendizado. Os conceitos destas ferramentas foram obtidos através de uma ampla revisão bibliográfica direcionada, onde foram analisados diversos artigos e livros sobre o referido tema.

Apesar de representar uma tecnologia bastante utilizada em treinamentos para mecânicos, simulações de diversas cirurgias, estratégias de marketing e em jogos variados, poucos casos são relatados do uso da RA e RV no ambiente educacional, em especial nos ambientes de aprendizado de Ciências Sociais Aplicadas e de Engenharias IV.

Para o docente, que muitas vezes encontra com um espaço de trabalho dotado de carências em infraestruturas, como ausência ou mesmo insuficiência de espaços de laboratórios, a adoção destas ferramentas seria uma alternativa viável, de baixo custo e com maiores possibilidades de sucesso como estratégia didática, necessitando do aluno apenas a posse de um celular com acesso à internet.

Como justificativa para o uso destes instrumentos no ensino-aprendizado de Ciências Sociais Aplicadas e Engenharias IV, entende-se que a tecnologia a cada dia ganha maior espaço na escola. Entre as diversas possibilidades de recursos didáticos utilizados, o celular ganha destaque como uma poderosa ferramenta de aprendizado. Segundo uma pesquisa realizada pela TIC Educação (2017), o percentual de docentes que utilizam o celular para as atividades na escola subiu de 
$39 \%$, em 2015, para $56 \%$ no ano de 2017.

Devido ao ensino remoto iniciado durante a pandemia proporcionada pela COVID-19, no caso do Brasil, a tecnologia passou a ser considerada, de um modo emergencial, como essencial para o prosseguimento das aulas. Desta forma, professores tiveram que realizar capacitações para desenvolver as aulas de modo virtual, sendo, assim, exigido que o aluno também disponha de recursos para acompanhar o curso. Diversos projetos dos governos e também das próprias instituições estão voltados à oferta de chips com acesso à internet e tablets para que os alunos possam acompanhar as aulas à distância. Infelizmente, não há uma cobertura total dos alunos em relação ao acesso às aulas, devido às dificuldades, além de financeiras, de ausência de sinais de rede de internet. Desta forma, estaria exposta um desafio importante para o acesso universal ao ensino remoto.

A internet passou a representar a principal ponte entre docente e discente, e o celular, um dos essenciais instrumentos para que o fluxo do ensino e do aprendizado prossiga de forma satisfatória. As ferramentas de RA e RV estão inseridas no grupo das tecnologias imersivas, que são considerados recursos tecnológicos que simulam o mundo físico através de um espaço virtual, através de um estado de imersão do usuário (RESENDE; SANTOS, 2019).

Em relação ao ensino das disciplinas de Ciências Sociais Aplicadas, a RA e $\mathrm{RV}$ assumem uma função importante de motivar o aluno a experimentar e investigar. O professor teria disponível um grande acervo de possibilidades para alcançar os objetivos pedagógicos, como, por exemplo, utilização de aplicativos interativos para - aprendizado da tabela periódica, onde o aluno possa visualizar, de forma tridimensional e com experiência imersiva, os elementos e suas características. Uma outra possibilidade seria o aprendizado da distinção entre as espécies de animais, proporcionando ao aluno uma oportunidade também de interação. São consideradas, ainda, diversas outras alternativas de uso.

Em relação ao ensino-aprendizado de Engenharias IV, a RA e RV podem ser utilizadas como ferramentas importantes, entre outras, para 0 aprendizado das instalações elétricas. Apenas com o uso de um celular com acesso à internet, o aluno teria acesso à interação com os conceitos e exemplos baseados em instalações reais que, de forma imersiva, iria compreender o conteúdo abordado. Esta estratégia, com evidente potencial de sucesso também nas aulas remotas, iria inserir o discente como construtor de seu próprio aprendizado ao utilizar metodologias ativas, levando o professor a ser um facilitador ou um mediador entre o conhecimento e o aprendiz.

Portanto, o objetivo desta pesquisa é, através de uma análise bibliográfica das teorias e práticas relevantes para o tema de estudo, compreender as características e os desafios relativos à utilização de RA e RV nas disciplinas de Ciências Sociais Aplicadas e Engenharias IV, além de indicar novas alternativas práticas que sejam eficazes no ambiente escolar. Para isto, há uma promoção da interdisciplinaridade através do uso de tecnologias de informação e comunicação (TICs), além do incentivo à adoção de metodologias ativas, formação e prática docentes para o ensino destas disciplinas e o estímulo à prática pedagógica em espaços formais e também não formais.

\section{MATERIAL E MÉTODOS}

A presente pesquisa referiu-se a um estudo baseado em abordagem do tipo qualitativa, por meio de revisão bibliográfica em livros e artigos científicos. $O$ filtro utilizado foi a relevância dos trabalhos textuais, considerando também os autores de 
cada texto e suas produções acadêmicas pertencentes às áreas de estudo deste artigo.

Através desta revisão bibliográfica, foram identificados os fundamentos sobre a Realidade Aumentada (RA) e Realidade Virtual (RV) no ensino-aprendizado de Ciências Sociais Aplicadas e Engenharias IV, com novas propostas de aplicação destas tecnologias. Foram pesquisados, também, temas complementares aos principais conceitos estudados, como a formação e prática docentes direcionados para o ensino das disciplinas presentes nestas áreas, além de um levantamento teórico sobre as Tecnologias de Informação e Comunicação (TICs) no processo de ensino-aprendizado.

Ainda, foram realizadas pesquisas bibliográficas relativas às Metodologias Ativas e Didática Profissional no ensino de Ciências Sociais Aplicadas e Engenharias IV em espaços formais e não formais, como forma de justificar a importância do incentivo a um aprendizado ativo, por meio da RA e RV, para que os estudantes das disciplinas pertencentes às áreas de Ciências Sociais Aplicadas e Engenharias IV possam construir um aprendizado ainda mais eficaz.

Como forma de ressaltar os filtros utilizados para a seleção dos livros e artigos científicos, foram definidos critérios de inclusão artigos relevantes para o tema de estudo, com traduções tanto nacionais quanto internacionais. Buscou-se adotar a utilização de artigos e livros mais recentes, porém alguns livros, por representarem produções clássicas sobre os temas em questão, foram devidamente adotados. Foram realizadas buscas na base de dados de diversas revistas científicas presentes na plataforma Google Acadêmico e Scientific Electronic Library Online (SciELO) Brasil, mediante a utilização dos seguintes descritores em português e inglês: "Realidade Virtual" and "Ciências Sociais Aplicadas", "Realidade Virtual" and "Engenharia IV", "Realidade Aumentada" and "Ciências Sociais Aplicadas" e "Realidade Aumentada" and "Engenharia IV". Em relação aos livros, foram consultados exemplares físicos e versões digitais.

$\mathrm{Na}$ seção denominada "Formação e prática docentes para o ensino de Ciências Sociais Aplicadas e Engenharias IV", foram adotados para a revisão bibliográfica 1 (um) livro e 8 (oito) artigos. Na seção "As Tecnologias de Informação e Comunicação (TICs) aplicadas ao processo de ensino e de aprendizado", foram revisados 6 (seis) artigos científicos e 1 (um) livro. No item "Metodologias Ativas e Didática Profissional no ensino de Ciências Sociais Aplicadas e Engenharias IV em espaços formais e não formais", foram adotados para revisão bibliográfica 8 (oito) artigos e 1 (um) livro relevantes e relacionados ao tema.

Para a seção "A Realidade Aumentada e a Realidade Virtual como ferramentas para o ensino de Ciências Sociais Aplicadas e Engenharias IV", foram revisados 6 (seis) artigos e 1 (um) livro de grande referência voltados à área. Para o item "Propostas inovadoras e desafios para o ensino de Ciências Sociais Aplicadas e Engenharias IV otimizado pela inserção da Realidade Aumentada e da Realidade Virtual", foi realizada uma revisão bibliográfica em um total de 15 (quinze) artigos com propostas inovadoras sobre o assunto estudado. A seguir, serão detalhados os referidos temas, em conjunto com o quadro de resumos das obras selecionadas para a análise bibliográfica.

\section{FORMAÇÃO E PRÁTICA DOCENTES PARA O ENSINO DE CIÊNCIAS SOCIAIS APLICADAS E ENGENHARIAS IV}

O processo de formação do professor deve ser considerado de forma contínua, abrangendo toda a trajetória do profissional no campo da educação. É 
preciso que o docente permita a adoção de novas estratégias de ensino, uma vez que a escola, refletindo a própria sociedade, encontra-se em constantes mudanças. Assim, segundo Imbernón (2016), as mudanças nas escolas pressupõem a adequação dos professores.

Em adicional, Imbernón (2016) menciona que os modelos de formação docente adotados em décadas anteriores, onde eram utilizados, de forma intensa, processos de memorização por acúmulo de conteúdos e também de incentivo à passividade dos alunos, não são considerados suficientes nos dias atuais para proporcionar ao aluno a construção de um saber mais efetivo.

Hansen et al. (2019) indicam a problematização e o reconhecimento das teorias e práticas de professores voltados para o ensino de Ciências Sociais Aplicadas, realizando uma análise relevante do processo de ensino. Stella e Massabni (2019), Mega et al. (2020) e Costa e Boldrin (2020) também abordam sobre a formação de professores nas áreas relativas às Ciências Sociais Aplicadas, com estratégias para 0 atendimento às principais necessidades educativas dos alunos.

Ao analisar a formação dos professores para atuarem nas áreas de Ciências Sociais Aplicadas e Engenharias IV, percebe-se que há esta necessidade de constante atualização das práticas pedagógicas vigentes. É preciso uma maior discussão, dentro dos cursos de licenciatura e de bacharelado voltados para estes campos de conhecimento, sobre a concepção de novas e eficientes metodologias.

O avanço do saber científico tem a capacidade de contribuir para a compreensão da importância da ciência e da tecnologia nos dias atuais, além de auxiliar na resolução de problemas e na apreensão de outros novos desafios. Desta forma, segundo Castells (2008), a Ciência assume um papel indispensável para o desenvolvimento da própria sociedade.

Apropriando-se desta importância, a formação dos docentes de Ciências Sociais Aplicadas, com um objetivo de alinhamento com as inovações e também com as necessidades específicas dos alunos, torna-se fundamental para estratégias de ensino cada vez mais efetivas e atraentes para o aluno. Como exemplo destas estratégias, Carvalho et al. (2021) aborda sobre a aprendizagem significativa aliada a um maior comprometimento do professor. Já o estudo realizado por Bawaneh et al. (2020) recomendou a necessidade emergente de proporcionar aos professores programas de desenvolvimento profissional para instruí-los e conscientizá-los sobre a utilidade de práticas pedagógicas reflexivas, que resultem em estratégias de ensino também reflexivas.

Ao considerar o atual cenário do ensino de Engenharias, observa-se ainda a presença de estratégias de memorização como principal forma de abordar o conteúdo na escola. Entende-se que seja necessário, em alguns casos, a adoção desta metodologia. Porém, ao incentivá-la de forma desproporcional em sala de aula, há um notável prejuízo no processo de ensino-aprendizado. Aprofundando o entendimento sobre as razões da adoção desta forma de ensinar, chega-se a uma das bases do problema, que se encontra no modo como o processo de formação do professor está construído.

Segundo Cândido et al. (2019), é preciso investir ainda mais na formação contínua do professor das áreas de Engenharias IV, uma vez que, tanto o mercado de trabalho quanto a sociedade, exigem profissionais cada vez mais capacitados. $E$ o aluno, quando bem preparado na escola, atende a estas exigências e desenvolve novos caminhos baseados na sua experiência.

Nos casos dos campos do ensino de Ciências Sociais Aplicadas e 
Engenharias IV, os avanços tecnológicos precisam ser discutidos e apropriados pelo docente durante a sua fase de formação. De acordo com Mercader e Gairín (2020), apesar das tecnologias digitais serem consideradas, atualmente, um dos instrumentos mais usados pelos alunos para o desenvolvimento do seu ambiente de aprendizagem personalizado, há uma falta de aproveitamento por parte do corpo docente no desenvolvimento de suas respectivas práticas docentes, em especial no nível universitário.

Os processos de ensino-aprendizado passaram por profundas alterações provocadas pela globalização e pela mercantilização do ensino. E os currículos da educação básica e superior precisam estar preparados para estas transformações.

Além disso, as propostas para as novas Diretrizes Curriculares Nacionais (DCN), em especial voltadas para os cursos de Engenharias, apresentam indicativos de avanço de um perfil generalista por parte do aluno, incentivando suas competências não apenas técnicas, mas também críticas e reflexivas (Cândido et al., 2019).

Portanto, é preciso que a formação e a prática docentes, não apenas das áreas de Ciências Sociais Aplicadas e Engenharias IV, mas também nas diversas outras, estejam atualizadas com as necessidades da sociedade, além de estarem alinhadas com as novas tecnologias, a fim de que o aluno seja melhor preparado tanto para exercer sua futura profissão quanto para desenvolver pesquisas relevantes para a própria comunidade.

O Quadro 01 indica o resumo do livro e dos artigos discutidos nesta etapa de revisão bibliográfica:

QUADRO 01: Resumo das obras abordadas na seção "Formação e prática docentes para o ensino de Ciências Sociais Aplicadas e Engenharias IV"

\begin{tabular}{|c|c|c|c|c|}
\hline BASE & AUTOR (ES) & $\begin{array}{l}\text { PERIÓDICO / } \\
\text { EDITORA }\end{array}$ & $\begin{array}{c}\text { ANO } \\
\text { PUBLICAÇÃO }\end{array}$ & TÍTULO \\
\hline Livro físico & IMBERNÓN & Editora Cortez & 2016 & $\begin{array}{l}\text { Qualidade do ensino e } \\
\text { formação do } \\
\text { professorado. }\end{array}$ \\
\hline $\begin{array}{c}\text { Google } \\
\text { Acadêmico }\end{array}$ & HANSEN et al. & $\begin{array}{c}\text { Revista } \\
\text { Eletrônica do } \\
\text { Mestrado em } \\
\text { Educação } \\
\text { Ambiental }\end{array}$ & 2019 & $\begin{array}{l}\text { Práticas educativas } \\
\text { CTS e Educação } \\
\text { Ambiental na } \\
\text { problematização dos } \\
\text { valores presentes no } \\
\text { direcionamento dado } \\
\text { ao desenvolvimento } \\
\text { científico-tecnológico }\end{array}$ \\
\hline SCIELO & $\begin{array}{l}\text { STELLA; } \\
\text { MASSABNI }\end{array}$ & $\begin{array}{l}\text { Revista Ciência } \\
\text { \& Educação. }\end{array}$ & 2019 & $\begin{array}{l}\text { Ensino de Ciências } \\
\text { Biológicas: materiais } \\
\text { didáticos para alunos } \\
\text { com necessidades } \\
\text { educativas especiais }\end{array}$ \\
\hline SCIELO & MEGA et al. & $\begin{array}{c}\text { Revista } \\
\text { Brasileira de } \\
\text { Ensino de Física }\end{array}$ & 2020 & $\begin{array}{c}\text { Comunidades de } \\
\text { Prática no ensino de } \\
\text { Ciências: uma revisão } \\
\text { da literatura de } 1991 \text { a } \\
2018\end{array}$ \\
\hline
\end{tabular}




\begin{tabular}{|c|c|c|c|c|}
\hline $\begin{array}{c}\text { Google } \\
\text { Acadêmico }\end{array}$ & $\begin{array}{l}\text { COSTA; } \\
\text { BOLDRIN }\end{array}$ & $\begin{array}{l}\text { Revista de } \\
\text { Ensino, } \\
\text { Educação e } \\
\text { Ciências } \\
\text { Humanas }\end{array}$ & 2020 & $\begin{array}{l}\text { O Método de aula } \\
\text { invertida: uma revisão } \\
\text { de literatura sobre } \\
\text { pesquisas brasileiras } \\
\text { em formação docente e } \\
\text { ensino de Ciências }\end{array}$ \\
\hline $\begin{array}{c}\text { Google } \\
\text { Acadêmico }\end{array}$ & $\begin{array}{l}\text { CANDIDO et } \\
\text { al. }\end{array}$ & $\begin{array}{l}\text { Revista de } \\
\text { Ensino de } \\
\text { Engenharia }\end{array}$ & 2019 & $\begin{array}{l}\text { O porquê da } \\
\text { necessidade de se } \\
\text { investir em um } \\
\text { programa de formação } \\
\text { docente nos cursos de } \\
\text { engenharias no Brasil }\end{array}$ \\
\hline $\begin{array}{c}\text { Google } \\
\text { Acadêmico }\end{array}$ & $\begin{array}{l}\text { MERCADE; } \\
\text { GAIRÍN }\end{array}$ & $\begin{array}{l}\text { International } \\
\text { Journal of } \\
\text { Educational } \\
\text { Technology in } \\
\text { Higher } \\
\text { Education }\end{array}$ & 2020 & $\begin{array}{l}\text { University teachers' } \\
\text { perception of barriers to } \\
\text { the use of digital } \\
\text { technologies: the } \\
\text { importance of the } \\
\text { academic discipline }\end{array}$ \\
\hline $\begin{array}{c}\text { Google } \\
\text { Acadêmico }\end{array}$ & $\begin{array}{c}\text { BAWANEH et } \\
\text { al. }\end{array}$ & $\begin{array}{l}\text { International } \\
\text { Journal of } \\
\text { Instruction }\end{array}$ & 2020 & $\begin{array}{l}\text { Gauging the Level of } \\
\text { Reflective Teaching } \\
\text { Practices among } \\
\text { Science Teachers }\end{array}$ \\
\hline $\begin{array}{c}\text { Google } \\
\text { Acadêmico }\end{array}$ & $\begin{array}{c}\text { CARVALHO et } \\
\text { al. }\end{array}$ & $\begin{array}{c}\text { Enciclopédia } \\
\text { Biosfera }\end{array}$ & 2021 & $\begin{array}{c}\text { O ensino de Ciências } \\
\text { por investigação à luz } \\
\text { da aprendizagem } \\
\text { significativa }\end{array}$ \\
\hline
\end{tabular}

Fonte: Os autores

Para que a trajetória formativa e a prática dos docentes de Ciências Sociais Aplicadas e Engenharias IV sejam aperfeiçoadas em prol de uma otimização do aprendizado pelos alunos, é necessária a compreensão dos conceitos sobre as Tecnologias de Informação e Comunicação (TICs) que serão discutidos na subseção seguinte.

\section{AS TECNOLOGIAS DE INFORMAÇÃO E COMUNICAÇÃO (TICS) APLICADAS AO PROCESSO DE ENSINO E DE APRENDIZADO}

No contexto dos últimos cinco anos, as Tecnologias da Informação e Comunicação (TICs) puderam ser utilizadas nas variadas áreas da sociedade e da esfera educacional. As ferramentas disponíveis potencializam o âmbito do ensino e do aprendizado, uma vez que é permitida ao aluno uma maior interação com o conteúdo abordado pelo professor, resultando no incentivo da autonomia deste estudante, trazendo-o para o centro da construção de seu conhecimento. De acordo com STOSIC et al. (2020), a utilização das TIC na educação auxilia no desenvolvimento das competências para a resolução de problemas no domínio das atividades profissionais.

Segundo Pinheiro (2018), o desenvolvimento tecnológico ocasionou um paulatino processo de inserção de tecnologias nos ambientes escolares. Todavia, tornou-se possível compreender sobre a importância das TICs como facilitadoras do campo do aprendizado no momento atual de pandemia causada pela Covid-19 no mundo que, como alternativa para mitigar a disseminação do vírus, foram adotadas medidas tais como aulas remotas e seminários virtuais. Desta forma, houve uma 
necessidade de mudança na forma como é conhecida a metodologia tradicional de ensino. Como resultado, os docentes precisaram adaptar suas estratégias pedagógicas para que os seus objetivos fossem atingidos satisfatoriamente e os alunos necessitaram adequar-se à rotina de aulas à distância, síncronas ou assíncronas, para que o percurso educacional fosse efetivado.

Ou seja, o acesso à internet e a utilização de ferramentas tecnológicas permitiram a continuidade e mesmo a otimização do processo educacional, conforme afirmado em:

Ao explorar as potencialidades das TIC no seu cotidiano, principalmente com o acesso à Internet, a escola abre-se para novas relações com o saber, vivenciando a comunicação compartilhada e a troca de informações com outros espaços do conhecimento que possuem os mesmos interesses. (ALMEIDA; MENEZES, 2004, p.1)

Da mesma forma que a adoção das TICs no âmbito do ensino e do aprendizado pode trazer benefícios, surgem novos desafios aos docentes e discentes, uma vez que ainda há uma dificuldade de apropriação dos novos recursos tecnológicos em sala de aula. Almeida e Menezes (2004) indicam uma resistência considerada por parte de alguns docentes ao permitir a mudança das estratégias didáticas ao inserir alternativas tecnológicas como otimizadoras do aprendizado, como por exemplo substituir o quadro branco por lousas interativas compradas pelas escolas, entre outras.

Um instrumento de diversas possibilidades para incentivo do aprendizado seria o celular. Jesus et al. (2017) afirmam que a correta utilização dos celulares como ferramenta pedagógica possibilita um maior interesse e uma maior interatividade por parte dos alunos, os quais pertencem a uma cultura digital. Os autores confirmam esta hipótese através de um estudo de caso em que ratifica a importância do celular para o estudante, existindo uma grande familiaridade no manuseio desta ferramenta por este sujeito.

Segundo Arruda (2021), com a utilização adequada das TICs, há uma maior possibilidade de desenvolvimento do aprendizado dos alunos. Tecnologias como o celular, tablet, computador, entre outros, são instrumentos com diversas possibilidades para substituir espaços físicos nas escolas, como laboratórios, além de serem considerados fundamentais no processo do ensino remoto em vigor no Brasil. Oliveira e Moura (2015) afirmam que as TICs contribuem notavelmente para as mudanças na sociedade. As novas ferramentas tecnológicas desenvolvidas devem ser inseridas no ambiente educacional, contribuindo diretamente para a formação de docentes, conforme Roberto e Ferreira (2017).

O Quadro 02 indica o resumo do livro e dos artigos abordados nesta etapa de revisão:

QUADRO 02: Resumo das obras discutidas na seção "As Tecnologias de Informação e Comunicação (TICs) aplicadas ao processo de ensino e de aprendizado"

\begin{tabular}{|c|c|c|c|c|}
\hline BASE & AUTOR (ES) & $\begin{array}{c}\text { PERIÓDICO / } \\
\text { EDITORA }\end{array}$ & $\begin{array}{c}\text { ANO } \\
\text { PUBLICAÇÃO }\end{array}$ & TíTULO \\
\hline Livro físico & $\begin{array}{c}\text { ALMEIDA; } \\
\text { MENEZES }\end{array}$ & Editora PUC-SP & 2004 & $\begin{array}{c}\text { O papel do gestor escolar na } \\
\text { incorporação das TICs na } \\
\text { escola: experiências em } \\
\text { construção e redes }\end{array}$ \\
\hline
\end{tabular}




\begin{tabular}{|c|c|c|c|c|}
\hline & & & & $\begin{array}{l}\text { colaborativas de } \\
\text { aprendizagem. }\end{array}$ \\
\hline $\begin{array}{c}\text { Google } \\
\text { Acadêmico }\end{array}$ & JESUS et al. & $\begin{array}{c}\text { Enciclopédia } \\
\text { Biosfera }\end{array}$ & 2017 & $\begin{array}{c}\text { O uso dos smartphones no } \\
\text { cotidiano dos jovens e os } \\
\text { principais aplicativos } \\
\text { utilizados para auxiliar nos } \\
\text { estudos - Um estudo de } \\
\text { caso }\end{array}$ \\
\hline $\begin{array}{c}\text { Google } \\
\text { Acadêmico }\end{array}$ & $\begin{array}{l}\text { OLIVEIRA; } \\
\text { MOURA }\end{array}$ & $\begin{array}{c}\text { Periódicos PUC } \\
\text { Minas. }\end{array}$ & 2015 & $\begin{array}{l}\text { TICs na educação: a } \\
\text { utilização das tecnologias da } \\
\text { informação e comunicação } \\
\text { na aprendizagem do aluno. }\end{array}$ \\
\hline $\begin{array}{c}\text { Google } \\
\text { Acadêmico }\end{array}$ & $\begin{array}{l}\text { ROBERTO; } \\
\text { FERREIRA }\end{array}$ & $\begin{array}{l}\text { Cadernos de } \\
\text { Educação: } \\
\text { Ensino e } \\
\text { Sociedade }\end{array}$ & 2017 & $\begin{array}{c}\text { Uma revisão bibliográfica } \\
\text { sobre a importância das } \\
\text { tecnologias da informação e } \\
\text { comunicação (TICs) para a } \\
\text { prática pedagógica em sala } \\
\text { de aula }\end{array}$ \\
\hline $\begin{array}{c}\text { Google } \\
\text { Acadêmico }\end{array}$ & REIS et al. & $\begin{array}{l}\text { RENOTE: Novas } \\
\text { Tecnologias na } \\
\text { Educação }\end{array}$ & 2017 & $\begin{array}{l}\text { Apropriação das Tecnologias } \\
\text { da Informação e } \\
\text { Comunicação no ensino de } \\
\text { ciências: uma revisão } \\
\text { sistemática da última década } \\
\text { (2007-2016) }\end{array}$ \\
\hline $\begin{array}{c}\text { Google } \\
\text { Acadêmico }\end{array}$ & $\begin{array}{l}\text { STOSIC et } \\
\text { al. }\end{array}$ & $\begin{array}{l}\text { World Journal on } \\
\text { Educational } \\
\text { Technology: } \\
\text { Current Issues }\end{array}$ & 2020 & $\begin{array}{c}\text { Information and } \\
\text { communication technologies } \\
\text { as a source of education }\end{array}$ \\
\hline $\begin{array}{c}\text { Google } \\
\text { Acadêmico }\end{array}$ & ARRUDA & $\begin{array}{l}\text { Boletim de } \\
\text { Conjuntura } \\
\text { (BOCA) }\end{array}$ & 2021 & $\begin{array}{c}\text { Ressignificações sobre o uso } \\
\text { pedagógico do celular a } \\
\text { partir do ensino remoto } \\
\text { emergencial }\end{array}$ \\
\hline
\end{tabular}

Fonte: Os autores

O docente possui uma importância essencial no momento de implantação das TICs na escola principalmente no que diz respeito à adequação da tecnologia ao conteúdo ministrado e às necessidades pedagógicas dos discentes (REIS et al., 2017). Estratégias baseadas nos conceitos das metodologias ativas e didática profissional, abordadas na seção a seguir, representam possibilidades viáveis para que $o$ aluno interaja com o assunto abordado de forma dinâmica e participativa.

\section{METODOLOGIAS ATIVAS E DIDÁTICA PROFISSIONAL NO ENSINO DE CIÊNCIAS SOCIAIS APLICADAS E DE ENGENHARIAS IV EM ESPAÇOS FORMAIS E NÃO FORMAIS}

A Didática Profissional (DP), segundo Alves (2020), representa uma corrente francesa importante para a análise e compreensão da atividade profissional docente. Esta corrente, conforme Pastré et al. (2006), possui como objetivo a articulação entre a dimensão teórica e a dimensão operatória. Ambas se complementam, de forma a constituir uma compreensão empírica de algo, mas também complementada pelos fundamentos teóricos existentes. 
Partindo deste argumento, Alves (2020) traz a reflexão sobre a função do professor enquanto responsável por ministrar disciplinas específicas como, a exemplo, aquelas relacionadas à matemática, ciências e engenharias:

\begin{abstract}
A atividade do professor que atua no ensino de disciplinas específicas envolve a mobilização de um amplo conjunto de conhecimentos, não necessariamente científicos, cuja natureza multifacetada e um viés multiplamente condicionado funciona como elemento agregador de maior dificuldade e se constitui, por vezes, como um verdadeiro obstáculo profissional (ALVES, 2020, p. 1904).
\end{abstract}

Assim, evidencia a importância de uma formação docente voltada para estes desafios, e que seja pautada em uma constante atualização. Como exemplo, no contexto da Educação Profissional e Tecnológica, o professor responsável por disciplinas das áreas de Engenharias IV, que construiu sua experiência profissional através de um aprendizado prático, necessitaria de uma formação inicial e continuada para proporcionar aos alunos o aprendizado destas disciplinas.

A DP está voltada para o aprendizado através de tarefas ou atividades, onde o trabalho é considerado uma fonte de desenvolvimento dos adultos (PASTRÉ, 2006 apud ALVES, 2019). Ou seja, esta corrente didática prioriza a compreensão de uma atividade que esteja voltada para o campo produtivo, ou seja, para o aprendizado observando experiências práticas (GRUBER et al., 2019 apud MENDES et al., 2020).

Associada aos objetivos da DP, as Metodologias Ativas (MA) se apresentam como importantes estratégias práticas destinadas a inserir o aluno como sujeito ativo de seu aprendizado. Conforme Moreira et al. (2018), estas metodologias surgem como um meio de inovação no processo de ensino-aprendizado, em que o docente deixaria de apenas transmitir informações acumuladas e sem relação entre si, passando a ser um facilitador para avanço do aluno em suas competências.

Prado (2015) ressalta a importância de aulas cada vez mais participativas, em que caberia ao professor o papel de mediação e orientação do percurso pedagógico. Segundo Colomer et al. (2020), há conexões entre a pesquisa teórica e aplicada sobre práticas reflexivas, geração de conhecimento em todas as áreas, prática profissional e identidade por meio de definição teórica, prática situada e fundamentada, além de um conhecimento transformador por meio da utilização de estratégias de metodologias ativas.

Entre as diversas metodologias ativas existentes, aquela que estaria relacionada com a DP seria a Aprendizagem Baseada em Problemas (ABP), a qual incentiva a construção de um currículo interdisciplinar e temático, estimulando trabalhos em equipe para a desenvoltura de problemas reais encontrados no cotidiano profissional.

Desta forma, a ABP é uma estratégia que busca uma dinamicidade entre ensino-aprendizado, superando os tradicionais modos de ensino, e trazendo ao aluno uma maior autonomia e maiores possibilidades de preparação para a atividade profissional.

Além disso, as metodologias ativas, como a ABP, podem ser utilizadas em espaços formais (dentro do espaço físico da escola) e espaços não formais. Jacobucci (2008) descreve os espaços fora do ambiente escolar como espaços não formais. Tais ambientes se inserem como importantes recursos pedagógicos e complementares ao cotidiano escolar, construindo um aprendizado significativo.

Portanto, é importante que a formação docente, voltada para os princípios da 
DP, esteja alinhada com uma prática docente baseada em princípios da ABP, com capacidade de ser aplicada também em espaços não formais. Um exemplo disto seria, nos dias atuais, a aplicação nas aulas remotas, condição esta imposta ao setor educacional brasileiro pela pandemia de Covid-19. O professor necessita que os alunos, cada um nos limites de suas residências, compreendam o conteúdo ministrado.

O Quadro 03 a seguir aponta o resumo dos livros e dos artigos abordados nesta etapa de revisão.

É preciso que exista uma estratégia pedagógica adequada para atrair a atenção do aluno e também ser eficiente, também durante as aulas remotas. Uma proposta de estratégia com grande capacidade de êxito seria a utilização de recursos tecnológicos da realidade aumentada e realidade virtual no processo de ensino das diversas disciplinas, entre elas Ciências Sociais Aplicadas e Engenharias IV. A subseção seguinte discutirá os conceitos destas ferramentas tecnológicas, além de indicar possibilidades de aplicação.

QUADRO 03: Resumo das obras abordadas na seção "Metodologias Ativas e Didática Profissional no ensino de Ciências e de Engenharias em espaços formais e não formais"

\begin{tabular}{|c|c|c|c|c|}
\hline BASE & AUTOR (ES) & $\begin{array}{l}\text { PERIÓDICO / } \\
\text { EDITORA }\end{array}$ & $\begin{array}{l}\text { ANO } \\
\text { PUBLICAÇ } \\
\text { ÃO }\end{array}$ & TíTULO \\
\hline $\begin{array}{l}\text { Google } \\
\text { Acadêmico }\end{array}$ & ALVES & $\begin{array}{l}\text { Revista lbero } \\
\text { americana de } \\
\text { Estudos em } \\
\text { Educação }\end{array}$ & 2020 & $\begin{array}{l}\text { A Didática Profissional (DP): } \\
\text { implicações para a formação } \\
\text { do professor e o ensino de } \\
\text { disciplinas específicas no Brasil }\end{array}$ \\
\hline $\begin{array}{l}\text { Google } \\
\text { Acadêmico }\end{array}$ & ALVES & $\begin{array}{l}\text { Diálogo } \\
\text { Educacional }\end{array}$ & 2019 & $\begin{array}{l}\text { Didactique professionnelle (DP) } \\
\text { et la théorie des situations } \\
\text { didactiques (TSD): une } \\
\text { perspective de } \\
\text { complémentarité au Brésil }\end{array}$ \\
\hline $\begin{array}{l}\text { Google } \\
\text { Acadêmico }\end{array}$ & $\begin{array}{l}\text { MENDES et } \\
\text { al. }\end{array}$ & $\begin{array}{l}\text { Revemat: } \\
\text { Revista } \\
\text { Eletrônica de } \\
\text { Educação } \\
\text { Matemática }\end{array}$ & 2020 & $\begin{array}{l}\text { A Didática Profissional: } \\
\text { ambiente de formação e } \\
\text { ambiente de trabalho }\end{array}$ \\
\hline $\begin{array}{l}\text { Google } \\
\text { Acadêmico }\end{array}$ & $\begin{array}{l}\text { PASTRÉ et } \\
\text { al. }\end{array}$ & $\begin{array}{l}\text { Revue Française } \\
\text { de Pédagogie }\end{array}$ & 2006 & La didactique professionnelle \\
\hline $\begin{array}{l}\text { Livro versão } \\
\quad \text { digital }\end{array}$ & $\begin{array}{l}\text { GRUBER et } \\
\text { al. }\end{array}$ & $\begin{array}{l}\text { Publicações do } \\
\text { IFSC }\end{array}$ & 2019 & $\begin{array}{c}\text { Didática Profissional: princípios } \\
\text { e referências para a Educação } \\
\text { Profissional }\end{array}$ \\
\hline $\begin{array}{l}\text { Google } \\
\text { Acadêmico }\end{array}$ & $\begin{array}{l}\text { MOREIRA et } \\
\text { al. }\end{array}$ & IMED & 2018 & $\begin{array}{c}\text { Aplicação de metodologias } \\
\text { ativas dinamizam o ensino } \\
\text { superior: um relato de caso no } \\
\text { curso de arquitetura e } \\
\text { urbanismo }\end{array}$ \\
\hline $\begin{array}{l}\text { Google } \\
\text { Acadêmico }\end{array}$ & PRADO & $\begin{array}{l}\text { Revista } \\
\text { Educação e } \\
\text { Evolução }\end{array}$ & 2015 & $\begin{array}{l}\text { Entendendo o aluno do século } \\
\qquad 21\end{array}$ \\
\hline
\end{tabular}




\begin{tabular}{|c|c|c|c|c|}
\hline $\begin{array}{c}\text { Google } \\
\text { Acadêmico }\end{array}$ & JACOBUCCI & $\begin{array}{c}\text { Revista em } \\
\text { Extensão }\end{array}$ & 2008 & $\begin{array}{c}\text { Contribuições dos espaços não } \\
\text { formais de educação para a } \\
\text { formação da cultura científica }\end{array}$ \\
\hline $\begin{array}{c}\text { Google } \\
\text { Acadêmico }\end{array}$ & $\begin{array}{c}\text { COLOMER } \\
\text { et al. }\end{array}$ & $\begin{array}{c}\text { MDPI } \\
\text { Sustainability }\end{array}$ & 2020 & $\begin{array}{c}\text { Active Methodologies for } \\
\text { Transformative Practices }\end{array}$ \\
\hline
\end{tabular}

Fonte: Os autores

\section{A REALIDADE AUMENTADA E A REALIDADE VIRTUAL COMO FERRAMENTAS PARA O ENSINO DE CIÊNCIAS SOCIAIS APLICADAS E ENGENHARIAS IV}

Diante de uma sociedade em constante evolução, na qual o indivíduo está inserido desde a infância no universo digital, é necessário que as estratégias pedagógicas considerem a utilização de recursos tecnológicos de uma forma mais intensa. Com a finalidade de adoção de meios tecnológicos em sala de aula, a realidade aumentada (RA) e a realidade virtual (RV) apresentam-se como ferramentas de notável capacidade de sucesso de potencialização do processo de ensino-aprendizado nas diversas disciplinas existentes. Na área das Ciências Sociais aplicadas, na subárea das Ciências Biomédicas, a exemplo, a RV possui diversas aplicações, como o aprendizado de neuroanatomia, indicado em Deursen et al. (2021).

A RA permite a integração entre elementos reais e virtuais. Considerado uma das principais referências sobre o tema, Azuma et al. (2001) afirma que a RA representa uma tecnologia capaz de enriquecer o mundo real com elementos virtuais produzidos por computador. Ou seja, o mundo real seria a base para a inserção de dados produzidos por recursos digitais, gerando uma maior interatividade e compreensão das informações pelo usuário.

Em uma outra referência de grande relevância, Tori e Hounsell (2018) apresentam as características da RA relacionadas aos softwares, hardwares e as utilizações nas diversas áreas do conhecimento. Os autores discutem sobre a evolução das tecnologias de informação e computação (TICs), indicando a RA como uma tecnologia capaz de estar presente tanto nos computadores quanto em dispositivos móveis (smartphones e tablets). Desta forma, através da interação com objetos virtuais, é possível adquirir um maior entendimento sobre a própria realidade.

Devido à facilidade de utilização desta tecnologia, com apenas um dispositivo móvel com acesso à internet e um software específico, é possível realizar a inserção dos elementos virtuais no mundo real, com um mínimo de instrução. A Figura 01 apresenta um exemplo da RA objetivando a compreensão de um elemento:

FIGURA 01: exemplo de utilização da RA

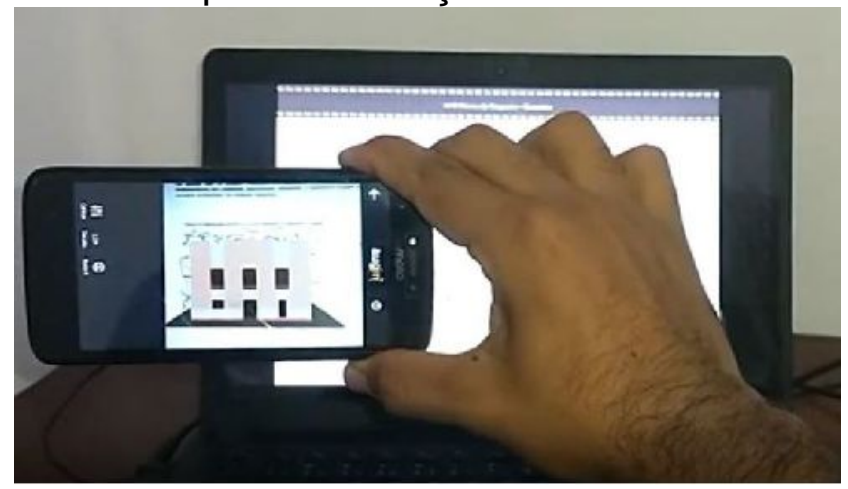

Fonte: Os autores 
As primeiras referências à RA foram notadas a partir do ano de 1962, em que o cineasta Morton Heilig desenvolveu um equipamento formado por uma tecnologia imersiva e multissensorial conhecida como Sensorama (TORI; HOUNSELL, 2018). Através deste equipamento, era possível o usuário captar diversas sensações, movimentos, odores, entre outros.

Apesar do conhecimento sobre o tema prosseguir avançando ao longo das décadas, somente no ano de 1992 foi utilizado pela primeira vez o termo "realidade aumentada", presente no artigo desenvolvido por Tom Caudell e Tom Mizell (LING, 2017). Anteriormente, os conceitos de RA eram ainda coincidentes com outra ferramenta tecnológica denominada realidade virtual (RV).

Segundo Tori e Hounsell (2018), a RV representa uma imersão total do usuário em um ambiente digitalmente criado, favorecendo diversos estímulos sensoriais. Todo um cenário é desenvolvido para que o sujeito tenha uma sensação de completo deslocamento para este universo, com informações digitais sobrepondo-se àquilo apresentado pelo mundo real. A Figura 02 apresenta um dos modelos de óculos para acesso à RV:

FIGURA 02: Modelo de óculos para acesso à RV

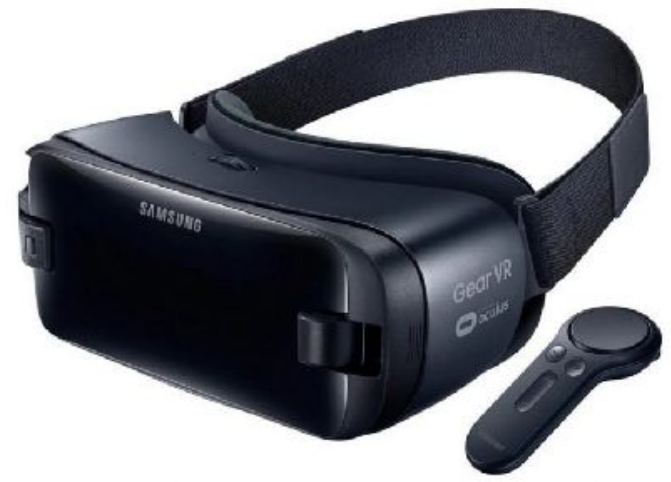

Fonte: Gogoni (2018)

Suas propriedades foram identificadas, inicialmente, através de um equipamento construído pelo engenheiro eletricista Ivan Sutherland, no ano de 1963, denominado Sketchpad (TORI; HOUNSELL, 2018), além dos primeiros experimentos de capacetes de RV, possibilitando a interação com um ambiente digital.

Atualmente, são encontrados equipamentos de RV disponíveis principalmente nas características de óculos e de capacetes, com tecnologia altamente desenvolvida, a fim de proporcionar ao usuário uma experiência de ser transportado a um ambiente previamente manipulado através de computador.

As distinções entre RA e RV encontram-se, em especial, no nível de imersão do sujeito. O foco desta última seria a utilização de uma criação digital como substituta de elementos reais (BILLINGHURST et al., 2015). Já a RA tem como foco o mundo real. Enquanto a RV depende de equipamentos de visualização mais sofisticados e utilizados em ambientes fechados, a RA apresenta menos limitações, sendo utilizada em ambientes abertos e fechados (LEITE, 2020), necessitando apenas de um marcador previamente configurado que, ao apontar a câmera do dispositivo, o software realize o processamento do objeto e o projete de forma tridimensional.

Tanto a RA quanto a RV podem ser utilizadas em recursos didáticos voltados 
para as áreas de Ciências, Engenharias e Matemática, por exemplo. É necessário que o professor busque apropriar-se do conhecimento e ferramentas disponíveis, para que o discente obtenha também o conhecimento e seja motivado a aprofundálo, gerando uma maior motivação durante a aula.

O Quadro 04 abaixo aponta o resumo do livro e dos artigos discutidos nesta etapa de revisão bibliográfica:

QUADRO 04: Resumo das obras revisadas na seção "A Realidade Aumentada e a Realidade Virtual como ferramentas para o ensino de Ciências Sociais Aplicadas e Engenharias IV"

\begin{tabular}{|c|c|c|c|c|}
\hline BASE & AUTOR (ES) & $\begin{array}{l}\text { PERIÓDICO / } \\
\text { EDITORA }\end{array}$ & $\begin{array}{c}\text { ANO } \\
\text { PUBLICAÇÃO }\end{array}$ & TÍTULO \\
\hline $\begin{array}{c}\text { Google } \\
\text { Acadêmico }\end{array}$ & MOORE et al. & $\begin{array}{c}\text { American Journal of } \\
\text { Engineering } \\
\text { Education }\end{array}$ & 2017 & $\begin{array}{l}\text { Engineering } \\
\text { Education For } \\
\text { Generation Z }\end{array}$ \\
\hline $\begin{array}{c}\text { Google } \\
\text { Acadêmico }\end{array}$ & AZUMA et al. & $\begin{array}{l}\text { IEEE Computer } \\
\text { Graphics and } \\
\text { Applications }\end{array}$ & 2001 & $\begin{array}{l}\text { Recent Advances in } \\
\text { Augmented Reality }\end{array}$ \\
\hline $\begin{array}{l}\text { Livro versão } \\
\quad \text { digital }\end{array}$ & $\begin{array}{c}\text { TORI; } \\
\text { HOUNSELL }\end{array}$ & Editora SBC & 2018 & $\begin{array}{c}\text { Introdução à } \\
\text { Realidade Virtual e } \\
\text { Aumentada }\end{array}$ \\
\hline $\begin{array}{c}\text { Google } \\
\text { Acadêmico }\end{array}$ & LING & IEEE MultiMedia & 2017 & $\begin{array}{l}\text { Augmented Reality } \\
\text { in Reality }\end{array}$ \\
\hline $\begin{array}{c}\text { Google } \\
\text { Acadêmico }\end{array}$ & $\begin{array}{l}\text { BILLINGHURST } \\
\text { et al. }\end{array}$ & $\begin{array}{l}\text { Foundations and } \\
\text { Trends } \AA \text { in Human- } \\
\text { Computer Interaction }\end{array}$ & 2015 & $\begin{array}{c}\text { A survey of } \\
\text { augmented reality }\end{array}$ \\
\hline $\begin{array}{c}\text { Google } \\
\text { Acadêmico }\end{array}$ & LEITE & $\begin{array}{l}\text { Revista de Estudos } \\
\text { e Pesquisas sobre } \\
\text { Ensino Tecnológico } \\
\text { (EDUCITEC) }\end{array}$ & 2020 & $\begin{array}{c}\text { Aplicativos de } \\
\text { Realidade Virtual e } \\
\text { Realidade } \\
\text { Aumentada para o } \\
\text { ensino de Química }\end{array}$ \\
\hline $\begin{array}{c}\text { Google } \\
\text { Acadêmico }\end{array}$ & DEURSEN et al. & $\begin{array}{l}\text { Nature: Scientific } \\
\text { Reports }\end{array}$ & 2021 & $\begin{array}{l}\text { Virtual reality and } \\
\text { annotated } \\
\text { radiological data as } \\
\text { effective and } \\
\text { motivating tools to } \\
\text { help Social Sciences } \\
\text { students learn } \\
\text { neuroanatomy }\end{array}$ \\
\hline
\end{tabular}

Fonte: Os autores

Na seção seguinte, através de uma revisão bibliográfica, serão apresentadas estratégias atuais e sugestões para a otimização do ensino de Ciências Sociais 
Aplicadas e de Engenharias IV, adotando as ferramentas disponíveis no campo da Realidade Aumentada e Realidade Virtual, permitindo uma maior interação entre conteúdo e aluno, com um alto potencial de sucesso na prática pedagógica.

\section{PROPOSTAS INOVADORAS E DESAFIOS PARA O ENSINO DE CIÊNCIAS E ENGENHARIAS OTIMIZADO PELA INSERÇÃO DA REALIDADE AUMENTADA E DA REALIDADE VIRTUAL}

A RA e a RV permitem um maior nível de interatividade nos espaços educacionais, proporcionando um sistema de aprendizado mais efetivo nas variadas áreas do conhecimento humano (AYER et al., 2016; MANRIQUE-JUAN et al., 2017). Nas disciplinas voltadas para as Ciências Sociais Aplicadas e para as Engenharias IV, estas tecnologias facilitam ao aluno visualizar de forma tridimensional as imagens e gráficos, compreendendo mais efetivamente as estratégias pedagógicas adotadas pelo professor. Entre as diversas possibilidades de práticas e inovações relativas à educação e ensino com o auxílio da RA e RV, Lopes et al. (2019) indicam aquelas comprovadamente eficazes, que serão abordadas a seguir.

\section{RA E RV ATRAVÉS DE SMARTPHONES E TABLETS}

Conforme pesquisa realizada pelo Instituto Brasileiro de Geografia e Estatística (IBGE) desenvolvida no ano de 2019, 94,7\% dos alunos utilizam o celular e $13,4 \%$ possuem tablets para fins de estudos. Considerando que, para a implantação da RA e RV no ambiente escolar, bastaria um smartphone ou tablet de configurações mínimas, seria possível o docente inserir de forma mais recorrente estas TICs em seu planejamento, baseando-se na metodologia denominada BYOD (Bring your own device - Utilize o seu dispositivo próprio) (HINO et al., 2019). Ou seja, o estudante utilizaria o seu próprio aparelho como ferramenta de aprendizado, gerando um maior fator de interesse e intermediado pelo professor.

Uma sugestão de uso da RA na área das Engenharias IV é demonstrada em Expósito et al. (2017), em que há uma maior abrangência na definição das espécies dos seres vivos. No artigo, são mencionados dois acrônimos relativos às TICs mencionadas nesta seção: TEP (Technologies for Empowerment and Participation Utilização adequada e participativa destas tecnologias) e TAP (Tecnologías del Aprendizaje y el Conocimiento - A utilização curricular e também organizacional destas tecnologias). Estas estratégias são consideradas inovadoras ao utilizar as referidas TICs como potencializadoras do aprendizado.

Um outro artigo que contribui para o tema é indicado em Chatzopoulos et al. (2017), que aponta os principais desafios à adoção da RA e RV, também nas áreas de Ciências Sociais Aplicadas e Engenharias IV, por meio dos dispositivos móveis, a exemplo dificuldades de redes e de usabilidade dos aplicativos, além das existentes limitações tecnológicas por aqueles que não possuem celular do tipo smartphone. Neste caso, uma possibilidade seria trabalhos em grupo, para que aqueles alunos com dificuldades de acesso sejam beneficiados com o acesso aos recursos destas TICs.

Pérez-Sanagustín et al. (2014) segue nesta temática da adoção de instrumentos móveis para a utilização com foco na RA, gerando uma transformação das atividades tradicionais em ações interativas, com a integração de diversas mídias.

Em relação ao ensino das disciplinas relativas à área de Engenharia IV, Liu et al. (2016) utilizou a RA para fortalecer a observação tridimensional e, consequentemente, o processo pedagógico. Os resultados aplicam-se também 
quando se utiliza a RV, pois, devido ao ambiente totalmente criado de forma artificial, o usuário é capaz de visualizar em tempo real os elementos tridimensionais.

Noor (2013) e Ramírez-Juidías et al. (2017) apresentam trabalhos com foco nas aulas enriquecidas com estas ferramentas digitais. $O$ entendimento dos elementos abordados em sala é otimizado com a adoção de aplicativos de RA e RV, fazendo com que o estudante manipule, de forma tridimensional e interativa, as informações e objetos, apenas com a posse de um smartphone ou tablet. O aluno das disciplinas de engenharia pode visualizar, por exemplo, elementos estruturais sendo desenvolvidos em tempo real, simulando as diversas possibilidades de cargas pontuais sobre colunas, lajes e vigas, por exemplo. Já nas disciplinas voltadas para as Engenharias IV, os estudantes são permitidos a experimentar diversas composições químicas de forma virtual, sendo necessário pouco investimento por parte da própria escola.

Assim, dispositivos móveis, como celulares e tablets, quando utilizados para fins educacionais, são considerados aliados do âmbito do ensino e do aprendizado (ARRUDA, 2021). Nesse sentido, destaca-se que os referidos dispositivos móveis proporcionam uma experiência tridimensional e com estímulos sensoriais ao adotar softwares de RA e RV como ferramentas, expandindo as possibilidades de inovações educacionais. Além destes dispositivos, podem ser utilizados jogos interativos, como detalhados a seguir.

\section{RA E RV ATRAVÉS DE JOGOS INTERATIVOS}

Uma outra adoção de aplicação da RA e da RV no ensino das disciplinas de Ciências Sociais Aplicadas e Engenharias IV seria através da utilização de jogos interativos. Diversos autores indicam esta alternativa como eficiente para um aprendizado ainda mais eficaz e não apenas lúdico.

Ayer et al. (2016) aborda sobre jogos relacionados ao aprendizado de disciplinas de engenharia, utilizando um software de RA denominado EcoCampus para a construção de um design voltado para a sustentabilidade. Ao final da pesquisa, detalha-se que os usuários do referido programa foram além daquilo solicitado nas tarefas, demonstrando um maior entendimento sobre o conteúdo.

Barma et al. (2015) também desenvolve um jogo de RA voltado para o ensino superior, como o ensino de Engenharias IV, simulando a resolução de mistérios relativos ao comportamento dos elementos transportados nos campos magnéticos e elétricos. Poderia ser adotado também ferramentas da RV, utilizando óculos especiais que permitam aos alunos visualizar este cenário com as partículas movendo-se e assumindo suas propriedades químicas.

Martin et al. (2014) aborda sobre três simulações de atividades adotando a plataforma ARIS, através de QR Codes e GPS. A pesquisa comprovou uma motivação nos alunos, afirmando a estratégia didática e potencializando o conhecimento de jogos locais de Ciências Sociais Aplicadas na comunidade.

Ao longo da pesquisa sobre as possibilidades de jogos utilizando a RA e RV, nota-se que são alternativas também eficazes para 0 aprendizado, se bem direcionadas pelos docentes. Os jogos podem ser acessados tanto pelos dispositivos móveis quanto por computadores de mesa e outros aparelhos. Caberia ao docente assumir a iniciativa de adotá-los em sala de aula, incentivando, inclusive, a criação de novos programas e interfaces dos jogos.

Como exemplo, o docente poderia aplicar com os estudantes jogos que permitam o manuseio de objetos virtuais de modo essencialmente interativo, para que haja um entendimento do processo como um todo. Caso esteja voltado para o 
ensino de Ciências Sociais Aplicadas, seria possível um jogo sobre os projetos arquitetônicos, que geram dificuldades de visualização nos métodos clássicos em sala de aula.

Em relação ao ensino de Engenharias IV, seria possível o desenvolvimento de um jogo voltado para a simulação de instalações elétricas, gerando relatórios interativos em cada alteração. Ou seja, há inúmeras alternativas de utilização dos jogos com baixo custo financeiro e viável de aplicação em sala de aula, exigindo uma maior qualificação do professor para trabalhar a inserção destes jogos pedagógicos com os discentes.

Os livros físicos e digitais também são considerados importantes instrumentos de adoção da RA e da RV no ensino de Sociais Aplicadas, o que será detalhado da seção abaixo através de uma análise bibliográfica.

\section{RA E RV ADOTADAS EM LIVROS FÍSICOS E DIGITAIS}

A utilização das possibilidades da RV e da RA inseridas nos livros tanto físicos quanto digitais representa uma tendência promissora no campo da educação, conforme os diversos autores presentes nesta revisão. Os livros podem ser trabalhados, por exemplo, com a inserção de QR Codes de acesso à RA ou à RV, permitindo a visualização tridimensional do conteúdo abordado. Uma vantagem seria a adoção do livro digital, considerando a facilidade de divulgação e o alinhamento aos conceitos de sustentabilidade, por não utilizar o papel impresso e a opção de gratuidade na distribuição.

Behzadan e Kamat (2013) indicam a inserção de um livro com ferramentas da RA com as possibilidades de máquinas voltadas para a área de Engenharia IV. Complementando os autores, no Brasil, há diversos livros didáticos de Ciências Sociais Aplicadas e outras disciplinas que já adotam ferramentas da RV e da RA em seu interior. O capítulo se inicia com a teoria sobre o conteúdo, aliado a imagens. Posteriormente, são encontrados marcadores de RA ou RV, onde o estudante, com o auxílio de um dispositivo móvel com um software previamente instalado, teria acesso à visualização tridimensional e interativa, como complemento ao entendimento do conteúdo.

Gutiérrez e Fernandéz (2014) também sugerem a adoção de livros, objetivando utilizar a RA como um suporte para os alunos da Engenharia IV. Como complemento, Stoyanova et al. (2015) abordam duas tarefas presentes em um livro com QR Codes sobre animais e sobre o sistema solar, inserindo a MAR (Mobile Augmented Reality - Realidade Aumentada Móvel).

Segundo pesquisas bibliográficas realizadas, percebeu-se que a utilização da RA em livros é mais usual do que a aplicação da RV, devido à facilidade de utilização, uma vez que, para o acesso à elementos $R V$, seriam necessários óculos especiais. Já a utilização da RA necessitaria, por exemplo, apenas de um smartphone com acesso à internet e um software específico para este fim.

Portanto, os livros com possibilidades de adoção de RA e RV representam importantes instrumentos de aprendizado, integrando a teoria com a visualização tridimensional, trazendo o aluno para um papel ativo e motivado ao processo de aprendizado (BEHZADAN; KAMAT, 2013).

O Quadro 05 abaixo aponta o resumo dos artigos discutidos nesta etapa de revisão: 
QUADRO 05: Resumo das obras abordadas na seção "Propostas inovadoras e desafios para o ensino de Sociais Aplicadas otimizado pela inserção da Realidade Aumentada e da Realidade Virtual"

\begin{tabular}{|c|c|c|c|c|}
\hline BASE & AUTOR (ES) & $\begin{array}{l}\text { PERIÓDICO / } \\
\text { EDITORA }\end{array}$ & $\begin{array}{c}\text { ANO } \\
\text { PUBLICAÇÃO }\end{array}$ & TÍTULO \\
\hline $\begin{array}{c}\text { Google } \\
\text { Acadêmico }\end{array}$ & AYER et al. & $\begin{array}{c}\text { Journal of Architectural } \\
\text { Engineering }\end{array}$ & 2016 & $\begin{array}{l}\text { Augmented Reality } \\
\text { Gaming in Sustainable } \\
\text { Design Education }\end{array}$ \\
\hline $\begin{array}{c}\text { Google } \\
\text { Acadêmico }\end{array}$ & $\begin{array}{l}\text { MANRIQUE- } \\
\text { JUAN et al. }\end{array}$ & BioOne & 2017 & $\begin{array}{l}\text { A Portable Augmented- } \\
\text { Reality Anatomy } \\
\text { Learning System Using a } \\
\text { Depth Camera in Real } \\
\text { Time }\end{array}$ \\
\hline SCIELO & LOPES et al. & $\begin{array}{l}\text { EDUR - Educação em } \\
\text { revista }\end{array}$ & 2019 & $\begin{array}{c}\text { Inovações Educacionais } \\
\text { com o uso da Realidade } \\
\text { Aumentada: uma revisão } \\
\text { sistemática }\end{array}$ \\
\hline $\begin{array}{c}\text { Google } \\
\text { Acadêmico }\end{array}$ & HINO et al. & $\begin{array}{l}\text { Acta Scientiarum. } \\
\text { Education }\end{array}$ & 2019 & $\begin{array}{l}\text { Bring your own device } \\
\text { (BYOD): entendendo } \\
\text { uma nova prática no } \\
\text { ambiente acadêmico }\end{array}$ \\
\hline $\begin{array}{c}\text { Google } \\
\text { Acadêmico }\end{array}$ & $\begin{array}{c}\text { EXPÓSITO et } \\
\text { al. }\end{array}$ & Revistas Electronicas & 2017 & $\begin{array}{l}\text { Aplicación de las TAC en } \\
\text { un entorno AICLE: Una } \\
\text { experiencia de } \\
\text { innovación en educación } \\
\text { primaria }\end{array}$ \\
\hline $\begin{array}{c}\text { Google } \\
\text { Acadêmico }\end{array}$ & $\begin{array}{l}\text { CHATZOPOU } \\
\text { LOS et al. }\end{array}$ & IEEE Access & 2017 & $\begin{array}{c}\text { Mobile Augmented } \\
\text { Reality Survey: From } \\
\text { Where We Are to Where } \\
\text { We Go }\end{array}$ \\
\hline $\begin{array}{c}\text { Google } \\
\text { Acadêmico }\end{array}$ & $\begin{array}{l}\text { PÉREZ- } \\
\text { SANAGUSTÍ } \\
\text { N et al. }\end{array}$ & $\begin{array}{l}\text { IEEE Transactions on } \\
\text { Learning Technologies }\end{array}$ & 2014 & $\begin{array}{l}\text { Augmenting reality and } \\
\text { formality of informal and } \\
\text { non-formal settings to } \\
\text { enhance blended } \\
\text { learning }\end{array}$ \\
\hline $\begin{array}{c}\text { Google } \\
\text { Acadêmico }\end{array}$ & LIU et al. & $\begin{array}{l}\text { Advances in } \\
\text { Mechanical Engineering }\end{array}$ & 2016 & $\begin{array}{l}\text { Innovation-supporting } \\
\text { tools for novice } \\
\text { designers: Converting } \\
\text { existing artifacts and } \\
\text { transforming new } \\
\text { concepts }\end{array}$ \\
\hline $\begin{array}{c}\text { Google } \\
\text { Acadêmico }\end{array}$ & NOOR & Open Engineering & 2013 & $\begin{array}{l}\text { Envisioning engineering } \\
\text { education and practice in } \\
\text { the coming intelligence } \\
\text { convergence era: a } \\
\text { complex adaptive } \\
\text { systems approach }\end{array}$ \\
\hline $\begin{array}{c}\text { Google } \\
\text { Acadêmico }\end{array}$ & $\begin{array}{l}\text { RAMÍREZ- } \\
\text { JUIDÍAS et al. }\end{array}$ & Engineering Letters & 2017 & $\begin{array}{l}\text { Developing experimental } \\
\text { learning in a graphical }\end{array}$ \\
\hline
\end{tabular}




\begin{tabular}{|c|c|c|c|c|}
\hline & & & & $\begin{array}{l}\text { course using thurstone's } \\
\text { law of comparative } \\
\text { judgment }\end{array}$ \\
\hline $\begin{array}{l}\text { Google } \\
\text { Acadêmico }\end{array}$ & BARMA et al. & $\begin{array}{l}\text { International Journal } \\
\text { of Serious Games }\end{array}$ & 2015 & $\begin{array}{l}\text { Observation and analysis } \\
\text { of a classroom teaching } \\
\text { and learning practice } \\
\text { based on augmented } \\
\text { reality and serious } \\
\text { games on mobile } \\
\text { platforms }\end{array}$ \\
\hline $\begin{array}{l}\text { Google } \\
\text { Acadêmico }\end{array}$ & MARTIN et al. & TechTrends & 2014 & $\begin{array}{l}\text { Participatory scaling } \\
\text { through augmented } \\
\text { reality learning Through } \\
\text { Local Games }\end{array}$ \\
\hline $\begin{array}{c}\text { Google } \\
\text { Acadêmico }\end{array}$ & $\begin{array}{l}\text { BEHZADAN; } \\
\text { KAMAT }\end{array}$ & $\begin{array}{l}\text { Automation in } \\
\text { Construction }\end{array}$ & 2013 & $\begin{array}{l}\text { Enabling discovery- } \\
\text { based learning in } \\
\text { construction using } \\
\text { telepresent augmented } \\
\text { reality }\end{array}$ \\
\hline $\begin{array}{l}\text { Google } \\
\text { Acadêmico }\end{array}$ & $\begin{array}{l}\text { GUTIÉRREZ; } \\
\text { FERNÁNDEZ }\end{array}$ & $\begin{array}{l}\text { International Journal of } \\
\text { Engineering Education }\end{array}$ & 2014 & $\begin{array}{l}\text { Applying Augmented } \\
\text { Reality in engineering } \\
\text { education to improve } \\
\text { academic performance \& } \\
\text { student motivation }\end{array}$ \\
\hline $\begin{array}{l}\text { Google } \\
\text { Acadêmico }\end{array}$ & $\begin{array}{c}\text { STOYANOVA } \\
\text { et al. }\end{array}$ & $\begin{array}{l}\text { Bulgarian Chemical } \\
\text { Communications }\end{array}$ & 2015 & $\begin{array}{l}\text { Enhancing elementary } \\
\text { student learning in } \\
\text { natural sciences through } \\
\text { mobile augmented reality } \\
\text { technology }\end{array}$ \\
\hline
\end{tabular}

Fonte: os autores

\section{CONCLUSÕES}

O presente trabalho, por meio de uma revisão bibliográfica detalhada de obras relevantes, permitiu a compreensão acerca da importância da inserção das TICs nas disciplinas relacionadas às Ciências Sociais Aplicadas e às Engenharias IV.

O notável avanço em um curto espaço de tempo do conhecimento elaborado nestas áreas gerou a necessidade de um aprendizado em sala de aula ainda mais efetivo, mitigando dificuldades que, em diversos casos, têm como base a dificuldade da visualização tridimensional de elementos do conteúdo abordado.

Desta forma, a adoção da RA e da RV é considerada uma solução viável e com grande potencial de sucesso para otimizar o processo de ensino-aprendizado destas disciplinas.

Os livros e artigos revisados neste trabalho comprovaram a eficácia desta estratégia pedagógica, indicando propostas inovadoras, sugerindo uma atualização no processo que se inicia na formação e prática do docente de Ciências Sociais Aplicadas e Engenharias IV.

Além disso, percorre a importância da utilização das TICs em ambiente escolar e também a adoção de instrumentos das Metodologias Ativas e conceitos da Didática Profissional nos espaços formais e não formais.

Portanto, o objetivo da presente pesquisa, que abrange a seleção seguida de 
revisão bibliográfica das obras relevantes para a análise e propostas inovadoras para o ensino das disciplinas de Ciências Sociais Aplicadas e Engenharias IV adotando a RA e RV, foi atingido, gerando um incentivo à promoção da interdisciplinaridade no ambiente escolar.

Como sugestão para futuras pesquisas, entende-se a relevância da construção de uma revisão bibliográfica sobre o uso da RA e RV em outras disciplinas como, por exemplo, Matemática e Geografia.

\section{REFERÊNCIAS}

ALMEIDA, M.; MENEZES, L. O papel do gestor escolar na incorporação das TICs na escola: experiências em construção e redes colaborativas de aprendizagem. São Paulo: PUC-SP, v.2, 16p. 2004.

ALVES, F. R. V. A Didática Profissional (DP): implicações para a formação do professor e o ensino de disciplinas específicas no Brasil. Revista Ibero americana de Estudos em Educação. Araraquara. v.15, n.4. p.1903-1918. 2020. Disponível em: <https://periodicos.fclar.unesp.br/iberoamericana/article/view/13377/9560>. DOI: 10.21723/riaee.v15i4.13377. Acesso em 21 jun. 2021.

ALVES, F. R. V. Didactique professionnelle (DP) et la théorie des situations didactiques (TSD): une perspective de complémentarité au Brésil. Diálogo Educacional. v.19, n. 60, p.328-361, 2019. Disponível em: $<$ https://periodicos.pucpr.br/index.php/dialogoeducacional/article/view/24070/23265>. Acesso em 20 jun. 2021.

ARRUDA, R. L.Ressignificações sobre o uso pedagógico do celular a partir do ensino remoto emergencial. Boletim de Conjuntura (BOCA), Boa Vista, v. 6, n. 17, p. 2021. 74-81, Disponível em: <http://revista.ioles.com.br/boca/index.php/revista/article/view/340>. DOI: 10.5281/zenodo.4774336. Acesso em: 3 set. 2021.

AYER, S. K.; MESSNER, J. I.; ANUMBA, C.J. Augmented Reality Gaming in Sustainable Design Education. Journal of Architectural Engineering, v. 22, n. 1, p. 1-9. 2016. Disponível em: <https://doi.org/10.1061/(ASCE)AE.1943-5568.0000195>. Acesso em: 08 ago. 2021.

AZUMA, R.; BAILLOT, Y.; BEHRINGER, R. Recent Advances in Augmented Reality. IEEE Computer Graphics and Applications, v. 21, n. 6, p. 34-47, 2001. Disponível em:

<https://www.researchgate.net/publication/3208983_Recent_advances_in_augmente d_reality_IEEE_Comput_Graphics_Appl>. DOI: 10.1109/38.963459. Acesso em 12 jul. 2021.

BARMA, S.; DANIEL, S.; BACON, N.; GINGRAS, M.A.; FORTIN, M. Observation and analysis of a classroom teaching and learning practice based on augmented reality and serious games on mobile platforms. International Journal of Serious Games, v. 2, n. 2, p. 69-88, 2015. Disponível em: <http://journal.seriousgamessociety.org/index.php?journal=|JSG\&page=article op=view\&path[]=66>. DOI: 10.17083/ijsg.v2i2.66. Acesso em: 10 ago. 2021. 
BAWANEH, A.K.; MOUMENE, A.B.H.; ALDALALAH, O. Gauging the Level of Reflective Teaching Practices among Science Teachers. International Journal of Instruction, v.13, n.1, p.695-712, 2020. Disponível em: <https://eric.ed.gov/?id=EJ1239304>. Acesso em: 02 set 2021.

BEHZADAN, A. H.; KAMAT, V. R. Enabling discovery-based learning in construction using telepresent augmented reality. Automation in Construction, v. 33, p. 3-10. 2013. Disponível em: <http://dx.doi.org/10.1016/j.autcon.2012.09.003>. DOI: 10.1016/j.autcon.2012.09.003. Acesso em: 20 jul. 2021.

BILLINGHURST, M.; CLARK, A.; LEE, G. A survey of augmented reality. Foundations and Trends ${ }^{\circledR}$ in Human-Computer Interaction, v. 8, n. 2-3, p. 73272, 2015. Disponível em: <https://www.nowpublishers.com/article/Details/HCl-049>. DOI: 10.1561/1100000049. Acesso em: 08 jun. 2021.

CANDIDO, J.; BARRETO, G.; CAMARGO, J. T. F.; VERASZTO, E. V. O porquê da necessidade de se investir em um programa de formação docente nos cursos de engenharias no Brasil. Revista de Ensino de Engenharia, v.38, n.3, p. 126-136, $2019 . \quad$ Disponível em: <http://revista.educacao.ws/revista/index.php/abenge/article/view/1563>. Acesso em: 10 ago. 2021.

CARVALHO, R. S. C.; CARVALHO, P. S.; MIRANDA, S. C. O ensino de Ciências por investigação à luz da aprendizagem significativa. Enciclopédia Biosfera, v. 18, n. 35, p. 155 - 172, 2021. Disponível em:

<https://conhecer.org.br/ojs/index.php/biosfera/article/view/3831>. Acesso em: 10 set 2021.

CASTELLS, M. A Sociedade em Rede. 11 ed. São Paulo: Paz e Terra, 354p., 2008.

CHATZOPOULOS, D.; BERMEJO, C.; HUANG, Z.; HUI, P. Mobile Augmented Reality Survey: From Where We Are to Where We Go. IEEE Access, v. 5, p. 6917-6950, 2017. Disponível em: <https://ieeexplore.ieee.org/document/7912316>. DOI: 10.1109/ACCESS.2017.2698164. Acesso em: 08 ago. 2021.

COLOMER, J.; SERRA, T.; CAÑABATE, D.; BUBNYS, R. Reflective Learning in Higher Education: Active Methodologies for Transformative Practices. MDPI Sustainability, v.12, p. 1-8, 2020. DOl:10.3390/su12093827. Disponível em: <https://www.mdpi.com/2071-1050/12/9/3827/htm>. Acesso em: 01 set 2021.

COSTA, N. M. L.; BOLDRIN, K. S. O Método de aula invertida: uma revisão de literatura sobre pesquisas brasileiras em formação docente e ensino de Ciências. Revista de Ensino, Educação e Ciências Humanas. São Paulo, v. 21, n.4, p.402408, 2020.2 Disponível em: <https://revistaensinoeeducacao.pgsskroton.com.br/article/view/8543>.

DOI: 10.17921/2447-8733.2020v21n4p402-408. Acesso: 12 ago. 2021.

DEURSEN, M.; REUVERS, L.; DUITS, J.D.; JONG, G.; HURK, M. et al. Virtual reality and annotated radiological data as effective and motivating tools to help Social Sciences students learn neuroanatomy. Nature: Scientific Reports, v. 11, n. 12843, 
p. 1-10, 2021. DOI: 10.1038/s41598-021-92109-y. Disponível em: <https://www.nature.com/articles/s41598-021-92109-y.pdf>. Acesso em: 02 set 2021.

EXPÓSITO, E. O.; FUENTES, E. M.; MARTíNEZ, J. J. R. Aplicación de las TAC en un entorno AICLE: Una experiencia de innovación en educación primaria. Revistas Eletronicas, v. 19, n. 1, p. 143-162. 2017. Disponível em: <https://revistaselectronicas.ujaen.es/index.php/ADE/article/view/3405>.DOI:

10.17561/ae. Acesso em: 08 ago. 2021.

GOGONI, R. 5 óculos de Realidade Virtual para usar com seu celular. Sítio Tecnoblog. 2018. Disponível em: <https://tecnoblog.net/269427/5-oculos-derealidade-virtual-para-usar-com-o-seu-celular/> . Acesso em: 03 set 2021.

GRUBER, C.; ALLAIN, O.; WOLLINGER, P. (Org.). Didática Profissional: princípios e referências para a Educação Profissional. Florianópolis. Publicações do IFSC, 139p. 2019. Disponível em: $<$ https://www.ifsc.edu.br/documents/30701/523474/Livro+Didatica+ProfissionalVFINAL-ISBN-online.pdf/9367b0c5-009e-4552-9330-2503828e71ad>. Acesso em: 21 jul. 2021.

GUTIÉRREZ, J. M.; FERNÁNDEZ, M. D. M. Applying Augmented Reality in engineering education to improve academic performance \& student motivation. International Journal of Engineering Education, v. 30, n. 3, p. 625-635. 2014. Disponível em: <https://www.researchgate.net/publication/270448828_Applying_Augmented_Reality _inEngineering_Education_to_Improve_Academic_Performance_Student_Motivatio> . Acesso em: 12 ago. 2021.

HANSEN, T.R.; MARSANGO, D.; SANTOS, R. A. Práticas educativas CTS e Educação Ambiental na problematização dos valores presentes no direcionamento dado ao desenvolvimento científico-tecnológico. REMEA: Revista Eletrônica do Mestrado em Educação Ambiental, n.2, p.118-129, 2019. Disponível em: <https://periodicos.furg.br/remea/article/view/8885>. DOI:10.14295/remea.v0i2.8885. Acesso em 12 ago. 2021.

HINO, M. C.; PRZEYBILOVICZ, E.; COELHO, T. R. Bring your own device (BYOD): entendendo uma nova prática no ambiente acadêmico. Acta Scientiarum. Education, n. 41, v.1, p. 1-13, 2019. Disponível em: $<$ https://doi.org/10.4025/actascieduc.v41i1.42661>.

DOI:10.4025/actascieduc.v41i1.42661. Acesso em: 12 ago. 2021.

IMBERNÓN, F. Qualidade do ensino e formação do professorado. São Paulo: Editora Cortez. 1ed. 232p. 2016.

JACOBUCCI, D. F. C. Contribuições dos espaços não formais de educação para a formação da cultura científica. Revista em Extensão, vol. 7, n.1, p. 55 - 66, 2008. Disponível

em: <http://www.seer.ufu.br/index.php/revextensao/article/view/20390>.

DOI: 10.14393/REE. Acesso em: 20 maio 2021. 
JESUS, C. F. A.; FERREIRA, A. M. B.; ALVES, M. F.; SILVA, E. M.; MESQUITA, N. A. $S$. O uso dos smartphones no cotidiano dos jovens e os principais aplicativos utilizados para auxiliar nos estudos - Um estudo de caso. Enciclopédia Biosfera, p. $1-15$, 2017.

Disponível em:<http://www.conhecer.org.br/enciclop/2017a/human/o\%20uso\%20smartph nes.pdf>. DOI: 10.18677/EnciBio_2017A140. Acesso em 10 ago. 2021.

LEITE, B. S. Aplicativos de Realidade Virtual e Realidade Aumentada para o ensino de Química. Revista de Estudos e Pesquisas sobre Ensino Tecnológico (EDUCITEC), v. 6, p. 1-18, 2020. Disponível em: <https://sistemascmc.ifam.edu.br/educitec/index.php/educitec/article/view/972>. DOI: 0000-0002-9402-936X. Acesso em: 12 jun. 2021.

LIMA, D. A.; STELLA, A. E. A relação professor-aluno aplicada ao contexto da educação superior. Enciclopédia Biosfera, v. 17, n. 32, p. $534-548,2020$. Disponível em: <https://conhecer.org.br/ojs/index.php/biosfera/article/view/10>. Acesso em: 10 set 2021.

LING, H. Augmented Reality in Reality. IEEE MultiMedia, v. 24, n. 3, p. 10-15, 2017. Disponível em: < https://ieeexplore.ieee.org/document/7999155>. DOI: 10.1109/MMUL.2017.3051517. Acesso em 12 ago. 2021.

LIU, Y.C.; KAO, C.Y.; CHAKRABARTI, A.; CHEN, C.H. Innovation-supporting tools for novice designers: Converting existing artifacts and transforming new concepts. Advances in Mechanical Engineering, v. 8, n. 6, p. 1-14, 2016. Disponível em: <https://journals.sagepub.com/doi/10.1177/1687814016651370>.

DOI: 10.1177/1687814016651370. Acesso em: 12 ago. 2021.

LOPES, L. M. D.; VIDOTTO, K. N. S.; POZZEBON, E.; FERENHOF, H. A. Inovações Educacionais com o uso da Realidade Aumentada: uma revisão sistemática. EDUR - Educação em revista. Belo Horizonte. n.35, p. 1-33. 2019. Disponível em: <https://www.scielo.br/j/edur/a/D8BG7VqVDPmYk3d5xmCJJyF/?lang=pt>. $\quad$ DOI: 10.1590/0102-4698197403. Acesso em 12 ago. 2021.

MANRIQUE-JUAN, A. C.; GROSTIETA-DOMINGUEZ, Z.V.E.; ROJAS-RUIZ, R.; ALENCASTRE-MIRANDA, M. A Portable Augmented-Reality Anatomy Learning System Using a Depth Camera in Real Time. BioOne, v. 79, n. 3, p. 176-183. 2017. Disponível em: <https://online.ucpress.edu/abt/article/79/3/176/18940/A-PortableAugmented-Reality-Anatomy-Learning>. DOI:10.1525/abt.2017.79.3.176. Acesso em: 10 jul. 2021.

MARTINS, A. F. P. Ensino de ciências: desafios à formação de professores. Revista Educação em Questão. Universidade Federal do Rio Grande do Norte. v. 23, n. 9, p. 53-65. 2005. Disponível em: < https://periodicos.ufrn.br/educacaoemquestao/article/view/8342>. Acesso em 19 maio 2021.

MARTIN, J.; DIKKERS, S.; SQUIRE, K.; GAGNON, D. Participatory scaling through augmented reality learning Through Local Games. TechTrends, v. 58, n. 1, p. 35-41. 2014. Disponível em: <https://courses.worldcampus.psu.edu/canvas/sp17/21711- 
6153/common/corefiles/Martin_etal_ARIS_games_2014.pdf >. Acesso em: 10 ago. 2021.

MEGA, D. F.; SOUZA, D. G.; VERA-REY, E. A.; VEIT, E. A. Comunidades de Prática no ensino de Ciências: uma revisão da literatura de 1991 a 2018. Revista Brasileira de Ensino de Física. São Paulo, v. 42, p. 1-18, 2020. Disponível em: <http://www.scielo.br/j/rbef/a/3zJGpGXkzVmTfWVWXvSCtrJ/?lang=pt\&format=html>. DOI: 10.1590/1806-9126-RBEF-2019-0264. Acesso em: 12 ago. 2021.

MENDES, H. L.S.; ALVES, F. R. V.; SANTOS, M. J. C. A Didática Profissional: ambiente de formação e ambiente de trabalho. Revemat: Revista Eletrônica de Educação Matemática. Florianópolis. v.15, p. 1-18, 2020. Disponível em: <https://periodicos.ufsc.br/index.php/revemat/article/view/1981-1322.2020.e74038>. DOI: 10.5007/1981-1322.2020.e74038. Acesso em: 20 jul. 2021.

MERCADER, C., GAIRÍN, J. University teachers' perception of barriers to the use of digital technologies: the importance of the academic discipline. International Journal of Educational Technology in Higher Education, v. 17, n. 4, p. 1-14, 2020. Disponível em: <https://doi.org/10.1186/s41239-020-0182-x>. Acesso em: 02 set 2021.

MOREIRA, D. A.; KUJAWA, H.; ALMEIDA, C. C. O. Aplicação de metodologias ativas dinamizam o ensino superior: um relato de caso no curso de arquitetura e urbanismo. IMED. p. 1-13, 2018. Disponível em: $<$ https://soac.imed.edu.br/index.php/mic/xiimic/paper/viewFile/1060/305>. Acesso em 21 jul. 2021.

NOOR, A. Envisioning engineering education and practice in the coming intelligence convergence era: a complex adaptive systems approach. Open Engineering, v. 3, n. 4, p. 606-619. 2013. Disponível em: <http://www.degruyter.com/view/j/eng.2013.3.issue-4/s13531-013-0122-9/s13531013-0122-9.xml>.DOI: doi.org/10.2478/s13531-013-0122-9. Acesso em: 12 ago. 2021.

OLIVEIRA, C.; MOURA, S. P. TICs na educação: a utilização das tecnologias da informação e comunicação na aprendizagem do aluno. Periódicos PUC Minas. v. 3 , n. $1, \quad$ p. $\quad 75-95, \quad 2015 . \quad$ Disponível em:<http://periodicos.pucminas.br/index.php/pedagogiacao/article/view/11019/8864>. Acesso em: 10 ago. 2021.

PASTRÉ, P.; MAYEN, P.; VERGNAUD, G. La didactique professionnelle. Revue Française de Pédagogie, n.154, p. 145-198. 2006. Disponível em:<http://rfp.revues.org/157>. DOI:10.4000/rfp.157. Acesso em 05 ago. 2021.

PÉREZ-SANAGUSTíN, M; HERNÁNDEZ-LEO, D.; SANTOS, P.; KLOOS, C.D.; BLAT, J. Augmenting reality and formality of informal and non-formal settings to enhance blended learning. IEEE Transactions on Learning Technologies, v. 7, n.2, p.118-131. $2014 . \quad$ Disponível em: <https://ieeexplore.ieee.org/abstract/document/6776563?reload=true>. $\quad$ DOI: 10.1109/TLT.2014.2312719. Acesso em: 08 ago. 2021. 
PINHEIRO, P. A. Pesquisa em contextos de ensino e aprendizagem por meio do uso da internet: uma ecologia de saberes. Revista Educação e Pesquisa, v. 44, p. 1-15, 2018. DOI:10.1590/S1678-4634201844180699. Disponível em: <https://www.scielo.br/j/ep/a/m9FwX6cnRtP6BZmZc4g9Z6K/?lang=pt>. Acesso em: 03 set 2021.

PRADO, A. Entendendo o aluno do século 21. Revista Educação e Evolução, p. 3$17.2015 .2 \quad$ Disponível em: <https://atravessiamindfulness.com.br/wpcontent/uploads/2019/12/EBOOK_geekie_a luno21.pdf >. Acesso em: 18 jun. 2021.

RAMÍREZ-JUIDÍAS, E.; MANZANARES, J.T.; AMARO-MELLADO, J. L.; RIDAOCEBALLOS, L. Developing experimental learning in a graphical course using thurstone's law of comparative judgment. Engineering Letters, v. 25, n. 1, p. 61-67. 2017.

Disponível

em: <https://www.researchgate.net/publication/313876090_Developing_Experimental_Le arning_in_a_Graphical_Course_Using_Thurstone's_Law_of_Comparative_Judgment >. Acesso em 10 ago. 2021.

REIS, R. S.; LEITE, B. S.; LEÃO, M.B.C. Apropriação das Tecnologias da Informação e Comunicação no ensino de ciências: uma revisão sistemática da última década (2007-2016). RENOTE: Novas Tecnologias na Educação. CINTED-UFRGS, v.15, n. $2, \quad$ p. $1-10,2017 . \quad$ Disponível em: <https://www.seer.ufrgs.br/renote/article/view/79232>. $\quad$ DOI: $10.22456 / 1679-$ 1916.79232. Acesso em: 10 ago. 2021.

RESENDE, B.; SANTOS, M. G. Virtualização e educação: desafios além da realidade. REDIN: Revista Educacional Interdisciplinar, v.8, n.1,p. 1-12. 2019. Disponível em: <https://seer.faccat.br/index.php/redin/article/view/1420>. Acesso em: 21 maio 2021.

ROBERTO, B. A. S. R.; FERREIRA, R. R. Uma revisão bibliográfica sobre a importância das tecnologias da informação e comunicação (TICs) para a prática pedagógica em sala de aula. Cadernos de Educação: Ensino e Sociedade. Bebedouro, São Paulo. p. 17-32. 2017. Disponível em: $<$ https://www.unifafibe.com.br/revistasonline/arquivos/cadernodeeducacao/sumario/5 0/26042017192702.pdf>. Acesso em: 12 ago. 2021.

STELLA, L. F.; MASSABNI, V. G. Ensino de Ciências Biológicas: materiais didáticos para alunos com necessidades educativas especiais. Revista Ciência \& Educação. Bauru, v.25, p. 353-374. 2019. Disponível em: <https://www.scielo.br/j/ciedu/a/cKGN5zGwbT9p5tZVXYCH5Nm/?lang=pt\&format=ht ml>. DOI: 10.1590/1516-731320190020006. Acesso em: 12 ago. 2021.

STOSIC, L.; DERMENDZHIEVA, S.; TOMCZYK, L. Information and communication technologies as a source of education. World Journal on Educational Technology: Current Issues, v. 12, n. 2, p. 128-135, 2020. DOI: 10.18844/wjet.v12i2.4815. Disponível em: <https://un-pub.eu/ojs/index.php/wjet/article/view/4815>. Acesso em: 01 set 2021. 
STOYANOVA, D.; KAFADAROVA, N.; STOYANOVA-PETROVA, S. Enhancing elementary student learning in natural sciences through mobile augmented reality technology. Bulgarian Chemical Communications, v. 47, p. 533-537. 2015. Disponível em: <http://www.bcc.bas.bg/BCC_Volumes/Volume_47_Special_B_2015/BCC-47-SI-B76.pdf>. Acesso em: 08 ago. 2021.

TORI, R.; HOUNSELL, M. S. (org.). Introdução à Realidade Virtual e Aumentada. Porto Alegre: Editora SBC. 536p. 2018. Disponível em: <http://www.de.ufpb.br/ labteve/publi/2018_livroRVA.pdf>. Acesso em: 12 ago. 2021. 